Federal Reserve Bank of Minneapolis

Research Department

\title{
Notes on the Aps Example in \\ "Towards a Theory of \\ Discounted Repeated Games \\ With Imperfect Monitoring"
}

\author{
Patrick J. Kehoe* \\ Working Paper 392 \\ February 1988
}

\footnotetext{
*Federal Reserve Bank of Minneapolis and University of Minnesota. The views expressed herein are those of the author and not necessarily those of the Federal Reserve Bank of Minneapolis or the Federal Reserve System.
} 


\section{The Structure of the "One Period" Incentive Problem}

Consider the following incentive problem: Given some action $\mathrm{q}=\left(\mathrm{q}_{2}, \mathrm{q}_{2}\right)$. Choose a function $\mathrm{u}: \Omega \rightarrow \mathrm{R}^{2}$ that solves

$$
\max _{u(\cdot)}\left[\pi_{1}\left(q_{1}, q_{2}\right)+\int u(p) g\left(p ; q_{1}, p_{2}\right) d p\right]
$$

subject to

$$
\begin{aligned}
& \pi_{1}\left(\mathrm{q}_{1}, \mathrm{q}_{2}\right)+\int \mathrm{u}(\mathrm{p}) \mathrm{g}\left(\mathrm{p} ; \mathrm{q}_{1}, \mathrm{q}_{2}\right) \geq \pi_{1}\left(\mathrm{q}_{1}^{\prime}, \mathrm{q}_{2}\right)+\int \mathrm{u}(\mathrm{p}) \mathrm{g}\left(\mathrm{p} ; \mathrm{q}_{1}^{\prime}, \mathrm{q}_{2}\right) \mathrm{dp} \\
& \mathrm{u}(\mathrm{p}) \geq \underline{\mathrm{u}} \\
& \mathrm{u}(\mathrm{p}) \leq \overline{\mathrm{u}} .
\end{aligned}
$$

Here $g\left(p ; q_{1}, q_{2}\right)$ is the density function of prices given that actions $\left(\mathrm{q}_{1}, \mathrm{q}_{2}\right)$ are chosen. For notational simplicity let $g(p)$ denote $g\left(p ; q_{1}, q_{2}\right)$ and let $g^{\prime}(p)$ denote $g\left(p ; q_{1}^{\prime}, q_{2}\right)$. Finally let

$$
f(p) \equiv g(p) / g^{\prime}(p)
$$

We will say the density functions $g(p)$ and $g^{\prime}(p)$ satisfy the (discrete) monotone likelihood ratio property if the ratio $\mathrm{f}(\mathrm{p})$ is monotone (increasing or decreasing) in $\mathrm{p}$. Now drop the constant term $\pi_{1}$ from the objective function, let $\mathrm{K}=\pi_{1}\left(\mathrm{q}_{1}^{\prime}, \mathrm{q}_{2}\right)-\pi_{1}\left(\mathrm{q}_{1}, \mathrm{q}_{2}\right)$ denote the one shot gain from deviating from $\mathrm{q}_{1}$. Let $\lambda$ denote the lagrange multiplier on the incentive constraint. (It is important to note that $\lambda$ is a constant. In particular it is not a function of p.) Assuming the incentive constraint binds we can rewrite (1.1) as

$$
\text { (1.3) } \max _{u(\cdot)} \int u(p)\left[g(p)+\lambda\left(g(p)-g^{\prime}(p)\right)\right] d p-\lambda k
$$

subject to $\mathrm{u}(\mathrm{p}) \geq \underline{\mathrm{u}}$ and $\mathrm{u}(\mathrm{p}) \leq \overline{\mathrm{u}}$.

Multiply and divide the objective function by $\mathrm{g}^{\prime}(\mathrm{p})$ and drop the constant term to obtain

$$
\max _{u(\cdot)} \int u(p)[f(p)+\lambda(f(p)-1)] g^{\prime}(p) d p
$$

subject to $u(p) \in[\underline{u}, \bar{u}]$. Let $D(p, \lambda)=[f(p)+\lambda(f(p)-1)]$. 
Now consider several cases

Case A. $\mathrm{f}(\mathrm{p})$ is Monotone Increasing in $\mathrm{p}$

Clearly $D(p, \lambda)$ is monotone increasing in $p$. For any fixed $\lambda$, let $\bar{p}(\lambda)$ solve $D(p, \lambda)=0$. Then we have
a. for $\mathrm{p}<\overline{\mathrm{p}}(\lambda), \quad \mathrm{D}(\mathrm{p}, \lambda)<0$,
b. for $p>\bar{p}(\lambda), \quad D(p, \lambda)>0$.

Now since $\mathrm{g}^{\prime}$ is a density function $\mathrm{g}^{\prime}(\mathrm{p}) \geq 0$ for all $\mathrm{p}$. Intuitively for each $\mathrm{p}$ we are choosing some number $\mathrm{u}(\mathrm{p})$ in $[\mathrm{u}, \overline{\mathrm{u}}]$ to solve

$$
\max _{u(p)} u(p) D(p, \lambda) g^{\prime}(p)
$$

This is a linear maximization problem, so the solution is clearly
a. set $\mathrm{u}(\mathrm{p})$ as large as possible if $\mathrm{D}(\mathrm{p}, \lambda) \mathrm{g}^{\prime}(\mathrm{p})$ is positive,
b. set $u(p)$ as small as possible if $D(p, \lambda) g^{\prime}(p)$ is negative,
c. set $u(p)$ to anything in $[\underline{u}, \bar{u}]$ if $D(p, \lambda) g^{\prime}(p)$ is zero.

Thus

$$
u(p)=\begin{array}{ll}
\bar{u} & \text { for } p>\bar{p}(\lambda) \\
u & \text { for } p \leq \bar{p}(\lambda)
\end{array}
$$

Equation (1.6) tells us the form of the optimal value function $u(p)$ for any given $\lambda$. To complete the solution we must choose the trigger price $\bar{p}$ so that the incentive constraint binds with equality. Since the support of the density functions is $[0,1]$, substituting (1.6) into the incentive constraint gives

$$
\left[\underline{u} \int_{0}^{p} g(p) d p+\bar{u} \int_{\bar{p}}^{1} g(p) d p\right]-\left[\underline{u} \int_{0}^{\bar{p}} g^{\prime}(p) d p+\bar{u} \int_{\bar{p}}^{1} g^{\prime}(p) d p\right]=k
$$


or $[\underline{u} G(\bar{p})+\bar{u}(1-G(\bar{p}))]-\left[\underline{u} G^{\prime}(\bar{p})+\bar{u}(1-G(\bar{p}))\right]=k$, or

$$
(\overline{\mathrm{u}}-\underline{\mathrm{u}})\left(\mathrm{G}^{\prime}(\mathrm{p})-\mathrm{G}(\mathrm{p})\right)=\mathrm{k} .
$$

One of the possible multiple solutions of (1.8) is the optimal trigger price $\overline{\mathrm{p}}$.

Case B. $\mathrm{f}(\mathrm{p})$ Monotone Decreasing in $\mathrm{p}$

The same logic implies

$$
u(p)=\begin{array}{ll}
\underline{u} & \text { for } p>\bar{p}(\lambda) \\
\bar{u} & \text { for } p \leq \bar{p}(\lambda)
\end{array}
$$

and $\overline{\mathrm{p}}$ solves $(\underline{\mathrm{u}}-\overline{\mathrm{u}})\left(\mathrm{G}^{\prime}(\mathrm{p})-\mathrm{G}(\mathrm{p})\right)=\mathrm{k}$.

Case C. $\mathrm{f}(\mathrm{p})$ is Neither Monotone Increasing or Decreasing

This case is somewhat complicated. For example, suppose graph of $\mathrm{D}(\mathrm{p}, \lambda)$ is as in Figure 1 .

So that
a. $\mathrm{D}(\mathrm{p}, \lambda)>0$ for $\mathrm{p} \in[0, \ddot{\mathrm{p}}(\lambda)] \cup[\overline{\mathrm{p}}(\lambda), 1]$,
b. $\mathrm{D}(\mathrm{p}, \lambda)<0$ for $\mathrm{p} \in\left[\overline{\mathrm{p}}_{1}(\lambda), \overline{\mathrm{p}}_{2}(\lambda)\right]$.

The same logic then implies the optimal value function $\mathrm{u}(\mathrm{p})$ has the form

$$
\mathrm{u}(\mathrm{p})=\begin{array}{ll}
\underline{\mathrm{u}} & \text { for } \mathrm{p} \in\left[\overline{\mathrm{p}}_{1}(\lambda), \overline{\mathrm{p}}_{2}(\lambda)\right] \\
\overline{\mathrm{u}} & \text { for } \mathrm{p} \in\left[0, \overline{\mathrm{p}}_{1}(\lambda) \cup \overline{\mathrm{p}}_{2}(\lambda), 1\right]
\end{array}
$$

We then need to solve for $\overline{\mathrm{p}}_{1}$ and $\overline{\mathrm{p}}_{2}$.

\section{An Example}

Consider the A-P-S example which has $g(p)=2 p, g^{\prime}(p)=2-2 p, k=6, \underline{u}=22, \bar{u}=38$. First note that

$$
f(p)=\frac{g(p)}{g^{\prime}(p)}=\frac{p}{1-p}
$$


is monotone increasing in $\mathrm{p}$ so we are in Case A. Thus from (1.6)

$$
u(p)=\begin{array}{ll}
38 & \text { for } p \geq \bar{p} \\
22 & \text { for } p<\bar{p}
\end{array}
$$

and $\bar{p}$ must solve the analogue of (1.8). Some $G(p)=p^{2}$ and $G^{\prime}(p)$ and $2 p-p^{2}$ we have $\bar{p}$ solves $16\left(2 p-2 p^{2}\right)=6$, which is equivalent to $p^{2}-p+3 / 16=0$ which has solutions $\bar{p}=1 / 4$ and $\ddot{p}=3 / 4$. By inspection, the objective function is maximized at $\bar{p}=1 / 4$ and minimized at $\bar{p}=3 / 4$. It is easy to check that the maximized value of (1.1) for this example is 38 while the minimized value is 22 .

\section{Some Useful Facts about $\mathrm{B}(\mathrm{W})$}

Recall the definitions:

Definition. An action profile $\mathrm{q}$ and value function $\mathrm{u}(\mathrm{p})$ is admissible with respect to a set $W$ if

a. the value function $\mathrm{u}(\mathrm{p})$ assigns payoffs in $\mathrm{W}$,

b. for each player $i$ the action $\mathrm{q}_{\mathrm{i}}$ is optimal given $\mathrm{q}_{-\mathrm{i}}$ when continuation payoffs are assigned by $u$. That is, for each $\mathrm{i}, \mathrm{E}_{\mathrm{i}}\left(\mathrm{q}_{\mathrm{i}}, \mathrm{q}_{-\mathrm{i}}, \mathrm{u}\right) \geq \mathrm{E}_{\mathrm{i}}\left(\mathrm{q}_{\mathrm{i}}^{\prime}, \mathrm{q}_{-\mathrm{i}}, \mathrm{u}\right)$ all $\mathrm{q}_{\mathrm{i}}^{\prime} \in \mathrm{S}_{\mathrm{i}}$ where $\mathrm{E}_{\mathrm{i}}(\mathrm{q}, \mathrm{u})=\delta\left[\pi_{\mathrm{i}}(\mathrm{q})+\right.$ $\left.\int u(p) g(p \mid q) d p\right]$.

Definition. The set $\mathrm{B}(\mathrm{W})=\{\mathrm{E}(\mathrm{q}, \mathrm{u}) \mid(\mathrm{q}, \mathrm{u})$ is admissible with respect to $\mathrm{W}\}$. For any fixed action vector $\overline{\mathrm{q}}$ let us also define $\mathrm{B}(\mathrm{W} \mid \overline{\mathrm{q}})=\{\mathrm{E}(\overline{\mathrm{q}}, \mathrm{u}) \mid(\overline{\mathrm{q}}, \mathrm{u})$ is admissible with respect to $\mathrm{W}\}$.

That is, $B(W \mid \bar{q})$ is the set of all payoffs that can be generated when the action vector is constrained to be some fixed $\bar{q}$ in $\mathrm{S}$. Of course by definition $\mathrm{B}(\mathrm{W})$ is simply the union of all these little sets $B(W \mid q)$ for $q \in S$. That is

$$
B(W)=\underset{q \in S}{U} B(W \mid q)
$$




\section{A. Simplifying $\mathbf{B}(\mathbf{W})$ for Throwing Out Irrelevant Actions}

Now in the A-P-S example there are nine possible pairs of actions say $\mathrm{q}^{\mathrm{i}}$ for $\mathrm{i}=1, \ldots, 9$. So $\mathrm{S}=\left\{\mathrm{q}^{1}, \ldots, \mathrm{q}^{9}\right\}$. However, we will show that only 3 of these actions say $\mathrm{q}^{1}, \mathrm{q}^{2}$, and $\mathrm{q}^{3}$ can ever be played in a sequential equilibrium and thus we conclude $B(W)=B\left(W \mid q^{1}\right) \cup B\left(W \mid q^{2}\right) \cup B\left(W \mid q^{3}\right)$.

Consider the A-P-S example. The expected payoff matrix is

\begin{tabular}{ccccc}
\hline \hline & $\mathrm{b}_{1}$ & $\mathrm{~b}_{2}$ & $\mathrm{~b}_{3}$ \\
\cline { 2 - 4 } $\mathrm{c}_{1}$ & 15, & 45 & 0,21 & 0,0 \\
$\mathrm{c}_{2}$ & 21, & 0 & 22,22 & 21,0 \\
$\mathrm{c}_{3}$ & 0, & 0 & 0,21 & 45,15 \\
\hline \hline
\end{tabular}

Let $\mathrm{V}$ denote the set of present discounted values of the sequential equilibria

A. Let $J=\operatorname{co}\{\pi(q) \mid q \in S\}$ denote the convex hull of the payoffs in the stage game. Let $I=$ $\left\{\left(v_{1}, v_{2}\right) \mid v_{i} \geq 21\right\}$ denote the set of payoffs greater than or equal to the value of being minimaxed forever. Since any equilibrium must have feasible, individually rational payoffs we know

$\mathrm{V} \subset(\mathrm{J} \cap \mathrm{I})=\operatorname{co}\{(21,39),(21,21),(39,21)\}$

\section{B. Convexity of $B(W \mid q)$}

We will later use the following fact:

(2.2) For any convex set $\mathrm{W}$ the set $\mathrm{B}(\mathrm{W} \mid \mathrm{q})$ is convex. The proof immediately follows since the incentive constraints on admissible pairs are linear in $\mathrm{u}$. Let $\left(\mathrm{q}, \mathrm{u}^{\mathrm{a}}\right)$ and $\left(\mathrm{q}, \mathrm{u}^{\mathrm{b}}\right)$ be two pairs which are admissible with respect to the convex set $\mathrm{W}$. Then for any $\lambda$ in $(0,1)$ we need to show

a. $\left(\mathrm{q}, \lambda \mathrm{u}^{\mathrm{a}}+(1-\lambda) \mathrm{u}^{\mathrm{b}}\right)$ is admissible with respect to $\mathrm{W}$, 
b. $\quad \mathrm{E}\left(\mathrm{q}, \lambda \mathrm{u}^{\mathrm{a}}(1-\lambda) \mathrm{u}^{\mathrm{b}}\right)=\lambda \mathrm{E}\left(\mathrm{q}, \mathrm{u}^{\mathrm{a}}\right)+(1-\lambda) \mathrm{E}\left(\mathrm{q}, \mathrm{u}^{\mathrm{b}}\right)$.

Consider player 1 's incentive constraints under $\mathrm{u}$ and $\mathrm{u}^{\prime}$

$$
\begin{aligned}
& \pi_{1}\left(\mathrm{q}_{1}, \mathrm{q}_{-1}\right)+\int \mathrm{u}^{\mathrm{a}}(\mathrm{p}) \mathrm{g}\left(\mathrm{p} ; \mathrm{q}_{1}, \mathrm{q}_{-1}\right) \mathrm{dp} \geq \pi_{1}\left(\mathrm{q}_{1}^{\prime}, \mathrm{q}_{-1}\right)+\int \mathrm{u}^{\mathrm{a}}(\mathrm{p}) \mathrm{g}\left(\mathrm{p} ; \mathrm{q}_{1}^{\prime}, \mathrm{q}_{-1}\right) \mathrm{dp} \\
& \pi_{1}\left(\mathrm{q}_{1}, \mathrm{q}_{-1}\right)+\int \mathrm{u}^{\mathrm{b}}(\mathrm{p}) \mathrm{g}\left(\mathrm{p} ; \mathrm{q}_{1}, \mathrm{q}_{-1}\right) \mathrm{dp} \geq \pi_{1}\left(\mathrm{q}_{1}^{\prime}, \mathrm{q}_{-1}\right)+\int \mathrm{u}^{\mathrm{b}}(\mathrm{p}) \mathrm{g}\left(\mathrm{p} ; \mathrm{q}_{1}^{\prime}, \mathrm{q}_{-1}\right) \mathrm{dp} .
\end{aligned}
$$

Multiplying (2.3) by $\lambda$ and (2.4) by $(1-\lambda)$ we see the player I's incentive constraints under $u=\lambda u^{\mathrm{a}}+$ $(1-\lambda) \mathrm{u}^{\mathrm{b}}$ are also satisfied and that $\mathrm{E}(\mathrm{q}, \mathrm{u})=\lambda \mathrm{E}\left(\mathrm{q}, \mathrm{u}^{\mathrm{a}}\right)+(1-\lambda) \mathrm{E}\left(\mathrm{q}, \mathrm{u}^{\mathrm{b}}\right)$.

B. I claim it is obvious that only the diagonal actions

$$
q^{1}=\left(a_{1}, b_{1}\right), \quad q^{2}=\left(a_{2}, b_{2}\right), \quad q^{3}=\left(a_{3}, b_{3}\right)
$$

will ever be played in a sequential equilibrium.

To see this note that for any off-diagonal pair of actions at least one player can obtain a one shot gain of at least 21 . For such an action to be part of any sequential equilibrium we must be able to punish this deviation by at least 21. By (2.1) the most the present discounted value of payoffs can be in any sequential equilibrium is 39 while the lowest it can be is 21 . Thus the most we can ever "punish" a player (i.e., the greatest difference between the best and the worst feasible individually rational payoffs) is 18 . Therefore $\mathrm{V}$ must be contained in the convex hull of payoffs resulting from $\mathrm{q}^{1}, \mathrm{q}^{2}$, and $\mathrm{q}^{3}$,

$$
\mathrm{V} \subset \mathrm{k}=\operatorname{co}\left\{\pi(\mathrm{q}) \mid \mathrm{q} \in\left(\mathrm{q}^{1}, \mathrm{q}^{2}, \mathrm{q}^{3}\right)\right\}=\operatorname{co}\{(15,45),(22,22),(45,15)\}
$$

and

$$
B(W)=B\left(W \mid q^{\prime}\right) \cup B\left(W \mid q^{2}\right) \cup B\left(W \mid q^{3}\right) .
$$




\section{Compute the Edges of the Pareto Frontier}

From the graph of the set of feasible payoffs it is clear that the Pareto frontier of this game is $\operatorname{co}\{(45,15),(15,45)\}$. Let us guess that the discount factor is high enough so that some points on the Pareto frontier can be the result of sequential equilibria. Let us find that extreme points of this

set. Since the game is symmetric these points will be some $(\alpha, \beta),(\beta, \alpha)$ pair. Since they lie on the frontier $\alpha+\beta=60$. Since $V=B(V)$ there is some pair $(q, u)$ that is admissible with respect to $V$ that supports them. Consider the point $(\alpha, \beta)$.

By definition the pair $(\mathrm{q}, \mathrm{u})$ supports $(\alpha, \beta)$ must have a $\mathrm{u}$ that assigns points in $\mathrm{V}$ and have $E(q, u)=(\alpha, \beta)$. Since $(\alpha, \beta)$ is on the edge of $V$ between $\pi\left(q^{1}\right)$ and $\pi\left(q^{2}\right)$ and since $E(q, u)$ is a convex combination of $\pi(\mathrm{q})$ and values of $\mathrm{u}$ we know $\mathrm{q}$ be $\mathrm{q}^{1}$ or $\mathrm{q}^{2}$ and $\mathrm{u}(\mathrm{p})$ must be in $\operatorname{co}\{(\alpha, 60-\alpha)$, $(60-\alpha, \alpha)\}$. Thus $\alpha$ must solve

$$
\alpha=\min _{u} \frac{1}{2}\left\{15+\int u_{1}(p) g\left(p ; q^{1}\right) d p\right\}
$$

subject to

$$
\begin{aligned}
& 21+\int u_{1}(p) g\left(p ; a_{2}, b_{1}\right) d p \leq 15+\int u_{1}(p) g\left(p ; q^{1}\right) d p \\
& u_{1}(p) \in[\alpha, 60-\alpha] .
\end{aligned}
$$

Since $f(p)=g\left(p ; q^{1}\right) / g\left(p ; a_{2}, b_{1}\right)=p / 1-p$ is monotone increasing in $p$ the results of Section I imply

$$
\mathrm{u}_{1}(\mathrm{p})=\begin{array}{cc}
\alpha & \mathrm{p} \leq \underline{\mathrm{p}} \\
60-\alpha & \mathrm{p}>\underline{\mathrm{p}}
\end{array}
$$

Substituting this into the incentive constraint and solving gives $\mathrm{p}=1 / 4$ or $\mathrm{p}=3 / 4$. The root $3 / 4$ minimize (2.5) and gives $\alpha=22$ and $\beta=38$. 
Claim $B\left(T / q^{l}\right)=W_{1}$. Where $\mathrm{q}^{1}=\left(\mathrm{a}_{1}, \mathrm{~b}_{1}\right)$

Consider the incentive constraints for $\left(\mathrm{q}^{1}, \mathrm{u}\right)$ with $\mathrm{u}=\left(\mathrm{u}_{1}, \mathrm{u}_{2}\right)$. For 1 to play $\mathrm{a}_{1}$ instead of $\mathrm{a}_{2}$ we need

$$
15+\int u_{1}(p) g\left(p ; a_{1}, a_{1}, b_{1}\right) d p \geq 21+\int u_{1}(p) g\left(p ; a_{2}, b_{1}\right) d p
$$

For 1 to play $a_{1}$ instead of $a_{3}$ we need

$$
15+\int u_{1}(p) g\left(p ; a_{1}, b_{1}\right) d p \geq 0+\int u_{1}(p) g\left(p ; a_{3}, b_{1}\right) d p
$$

For 2 to play $b_{1}$ instead of $b_{2}$ we need

$$
45+\int u_{2}(p) g\left(p ; a_{1}, b_{1}\right) d p \geq 21+\int u_{2}(p) g\left(p ; a_{1}, b_{2}\right) d p
$$

For 2 to play $b_{1}$ instead of $b_{3}$ we need

$$
45+\int u_{2}(p) g\left(p ; a_{1}, b_{1}\right) d p \geq 0+\int u_{2}(p) g\left(p ; a_{1}, b_{3}\right) d p
$$

First, I claim for any $\mathrm{u}_{2}$ which assigns payoffs in the feasible set $(I \cup J)$ constraints (4.3) and (4.4) are automatically satisfied. The reason is that for each of these the one shot loss from deviating to either $b_{2}$ or $b_{3}$ is at least $24(=45-21)$ while the maximum reward to deviating is at most 18 (= 39-21).

Next, I claim (4.2) is redundant given (4.1). Since the density under $\left(a_{2}, b_{1}\right)$ and under $\left(a_{3}, b_{1}\right)$ are the same the right side of (4.1) is strictly larger (i.e., by 21 units) than the right side of (4.2). Thus if $\mathrm{u}_{1}$ satisfies (4.1) it certainly satisfies (4.2).

Hence we have reduced the four incentive constraints to a single one, namely (4.1) and we can use the results of Section I. Let us first find what the maximum value that player I's payoff can be for some $\left(\mathrm{q}^{1} ; \mathrm{u}_{1}, \mathrm{u}_{2}\right)$ that is in $\mathrm{B}\left(\mathrm{T} \mid \mathrm{q}^{1}\right)$. By the above argument this problem is the following:

$$
\max _{u_{1}} 15+\int u_{1}(p) 2 p d p
$$


subject to $15+\int \mathrm{u}_{1}(\mathrm{p}) 2 \mathrm{pdp} \geq 21+\int \mathrm{u}_{1}(\mathrm{p})(2-2 \mathrm{p}) \mathrm{dp}$ and $\mathrm{u}_{1}(\mathrm{p}) \in[22,38]$. We have already shown in that the optimal $\overline{\mathrm{u}}_{1}$ has

$$
\overline{\mathrm{u}}_{1}(\mathrm{p})=\begin{array}{ll}
22 & \mathrm{p}<3 / 4 \\
38 & \mathrm{p} \geq 3 / 4
\end{array}
$$

and the resulting value of the objective is $26(=1 / 2[15+37])$. Now to trace out the values of player 2's payoff we vary how we set $\mathrm{u}_{2}(\mathrm{p})$ subject to the requirement that $\left(\overline{\mathrm{u}}_{1}(\mathrm{p}), \mathrm{u}(\mathrm{p})\right)$ lies in coT. The largest value of player 2's payoff is clearly attained at the edge where $\tilde{u}_{1}(p)+\mathrm{u}_{2}(p)=60$. At this edge 2's payoff is $1 / 2[45+(60-37)]=34$. Thus $(26,34)$ is the northeast corner of $\mathrm{B}\left(\mathrm{T} \mid \mathrm{q}^{1}\right)$. It is the point in $\mathrm{B}\left(\mathrm{T} \mid \mathrm{q}^{\mathrm{l}}\right)$ that is maximal for player 1 and player 2 .

To find the southeast corner we choose $\mathrm{u}_{2}$ so as to minimize player 2's payoffs subject to $\left(\overline{\mathrm{u}}_{1}, \mathrm{u}_{2}\right) \in$ coT. Clearly the minimizing $\mathrm{u}_{2}$ sets $\mathrm{u}_{2}(\mathrm{p})=22$ for all $\mathrm{p}$. The resulting payoff for 2 is $33.5(=1 / 2[45+22])$ thus $(26,33.5)$ is the southeast corner.

To find the northwest corner we first choose $\underline{u}_{1}$ to solve the same problem in (4.5) with the max replaced with a min. The resulting $\underline{\underline{u}}_{1}$ has

$$
\underline{\mathrm{u}}_{1}(\mathrm{p})=\begin{array}{ll}
38 & \text { if } \mathrm{p}<1 / 4 \\
22 & \text { if } \mathrm{p} \geq 1 / 4
\end{array} \text {. }
$$

The resulting value for 1 's payoffs is $22=1 / 2[15+29]$. [Recall that 29 is the value of $\underline{\underline{u}}_{1}(p) 2 p d p$ with $\underline{\mathrm{u}}_{1}$ given by (4.6).] To find the value for player 2 at this point we choose $\mathrm{u}_{2}$ to maximize 2 's payoffs subject to the constraint that $\left(\underline{\mathrm{u}}_{1}, \mathrm{u}_{2}\right) \in \mathrm{coT}$. The largest such value is attained at the edge of the feasible set where $\underline{u}_{1}(p)+u_{2}(p)=60$. Given this form for $u_{2}$ we compute player 2 's payoffs to be $38=1 / 2(45+[60-29])$. Thus $(22,38)$ is the northwest corner.

To find the southwest corner of $\mathrm{B}\left(\mathrm{T} \mid \mathrm{q}^{1}\right)$ we choose $\underline{u}_{1}$ to minimize 1's payoff thus $\underline{u}_{1}$ is given by (4.6) and the value of 1 's payoff is 22 . We then minimize 2 's payoffs by choosing $\mathrm{u}_{2}$ subject to 
constraint $\left(\underline{\mathrm{u}}_{1}, \mathrm{u}_{2}\right) \in$ coT. Clearly such $\mathrm{a} \mathrm{u}_{2}(\mathrm{p})=22$ for all $\mathrm{p}$. The resulting value of 2 's payoffs is $33.5=1 / 2[45+22]$. Thus $(22,33.5)$ is the southwest corner.

Thus we have shown that the extreme points of $\mathrm{B}\left(\mathrm{T} \mid \mathrm{q}^{1}\right)$ are given by

$\{(26,34),(26,33.5),(22,38),(22,33.5)\}$.

Then from our results in Section II we know $B\left(T \mid q^{1}\right)$ is a convex set. [Really we know $\mathrm{B}\left(\operatorname{coT} \mid \mathrm{q}^{1}\right)$ is convex and we use the "bang bang" result that $\mathrm{B}\left(\operatorname{coT} \mid \mathrm{q}^{1}\right)=\mathrm{B}\left(\mathrm{T} \mid \mathrm{q}^{1}\right)$.] Thus $\mathrm{B}\left(\mathrm{T} \mid \mathrm{q}^{1}\right)$ is the convex hull of the four points in (4.7) and thus $\mathrm{B}\left(\mathrm{T} \mid \mathrm{q}^{1}\right)$ equals the $\mathrm{W}_{1}$ given in Figure 2. By symmetry $\mathrm{B}\left(\mathrm{T} \mid \mathrm{q}^{2}\right)$ equals the $\mathrm{W}_{3}$ given in Figure 3 .

Claim $B\left(T / q^{2}\right)=W_{2}$. Finally we need to show $\mathrm{B}\left(\mathrm{T} \mid \mathrm{q}^{2}\right)$ with $\mathrm{q}^{2}=\left(\mathrm{a}_{2}, \mathrm{~b}_{2}\right)$ is the set $\mathrm{W}_{2}$ in Figure 2 . This set is particularly easy to compute because $\mathrm{q}^{2}$ is a Nash equilibrium of the one shot game. Since $q^{2}$ is a Nash equilibrium we know $\pi_{1}\left(a_{2}, b_{2}\right) \geq \pi_{1}\left(a_{j}, b_{2}\right)$ for $a_{j}=a_{1}$ or $a_{3}$ and $\pi_{2}\left(a_{2}, b_{2}\right) \geq \pi_{2}\left(a_{2}, b_{j}\right)$ for $b_{j}=b_{1}$ or $b_{3}$.

Clearly if we add some constant to both pairs of these inequalities they still hold true. Thus any $\left(\mathrm{q}^{2}, \mathrm{u}_{1}, \mathrm{u}_{2}\right)$ pair with the functions $\left(\mathrm{u}_{1}(\mathrm{p}), \mathrm{u}_{2}(\mathrm{p})\right)$ set equal to some constants $\left(\mathrm{t}_{1}, \mathrm{t}_{2}\right) \in \operatorname{coT}$ is admissible. Thus $B\left(T \mid q^{2}\right)$ includes all points of the form $1 / 2\left([22,22]+\left[t_{1}, t_{2}\right]\right)$ for $\left(t_{1}, t_{2}\right) \in \operatorname{coT}$. This implies $\mathrm{B}\left(\mathrm{T} \mid \mathrm{q}^{2}\right) \subseteq \mathrm{W}_{2}$.

To show $\mathrm{B}\left(\mathrm{T} \mid \mathrm{q}^{2}\right) \supseteq \mathrm{W}_{2}$ consider any admissible pair $\left(\mathrm{q}^{2}, \mathrm{u}_{1}, \mathrm{u}_{2}\right)$ with $\mathrm{u}=\left(\mathrm{u}_{1}, \mathrm{u}_{2}\right)$ possibly nonconstant. By definition of admissibility $\left(\mathrm{t}_{1}, \mathrm{t}_{2}\right)=\int \mathrm{u}(\mathrm{p}) \mathrm{g}\left(\mathrm{p} ; \mathrm{q}^{2}\right) \in \mathrm{coT}$. Consider some new pair of constant functions $\left(\mathrm{u}_{1}^{\prime}(\mathrm{p}), \mathrm{u}_{2}^{\prime}(\mathrm{p})\right)$ with $\mathrm{u}_{1}^{\prime}(\mathrm{p})=\mathrm{t}_{1}$ and $\mathrm{u}_{2}^{\prime}(\mathrm{p})=\mathrm{t}_{2}$. This new pair $\left(\mathrm{q}^{2} ; \mathrm{u}_{1}^{\prime}, \mathrm{u}_{2}^{\prime}\right)$ is admissible and by construction has the same value as $\left(\mathrm{q}^{2}, \mathrm{u}_{1}, \mathrm{u}_{2}\right)$ namely $\mathrm{E}\left(\mathrm{q}^{2}, \mathrm{u}\right)=\mathrm{E}\left(\mathrm{q}_{2}, \mathrm{u}^{\prime}\right)$. Thus $\mathrm{B}\left(\mathrm{T} \mid \mathrm{q}^{2}\right)=\mathrm{W}_{2}$.

Since by construction $T=$ ext $V$ we are done. Since $W=B(T)=B($ ext $V)=B(V)=V$. 